P. Pascale

B. Quartenoud

J.-C. Stauffer

\title{
Isolated large inverted T wave in pulmonary edema due to hypertensive crisis: a novel electrocardiographic phenomenon mimicking ischemia?
}

Sirs: Large $\mathrm{T}$ wave inversion recorded in an isolated region of the precordial electrocardiographic (ECG) leads during an acute cardiac event most frequently signifies myocardial ischemia. The characteristic association between the ECG pattern of deeply inverted $\mathrm{T}$ waves, mainly in leads $\mathrm{V} 2$ and V3, and critical stenosis of the proximal left anterior descending coronary artery was first described by Wellens in 1982 [1]. Because of the high incidence of extensive anterior myocardial infarction when such patients are treated medically and the occurrence of $\mathrm{T}$ wave changes during pain-free interval (or when other evidence of ischemia are absent), the development of dynamic isolated $\mathrm{T}$ wave inversion is a subject of considerable concern.

Received: 28 July 2006

Accepted: 10 January 2007

Published online: 26 February 2007

Dr. Patrizio Pascale, MD ( $\bullet)$

Division of Cardiology, Department of Medicine

University Hospital Lausanne

1011 Lausanne, Switzerland

Tel.: +41-2 13140069

Fax: +41-2 13140013

E-Mail: patrizio.pascale@chuv.ch

Dr. Patrizio Pascale, MD · B. Quartenoud, MD

Intensive Care Unit

Cantonal Hospital

Fribourg, Switzerland

J.-C. Stauffer, MD

Division of Cardiology

University Hospital

Lausanne, Switzerland
A variety of non-coronary events are known to result in global or isolated giant $\mathrm{T}$ wave inversion. To our knowledge, acute cardiogenic but non-ischemic pulmonary edema has not been previously associated with dynamic isolated giant $\mathrm{T}$ wave inversion. The purpose of the present study is to describe three patients who developed this characteristic ECG pattern after resolution of acute pulmonary edema without significant coronary disease.

\section{Method}

Over a three-year period (May 2000 to November 2003) three cases were identified in our department with the following clinical characteristics: 1) acute pulmonary edema based on mode of presentation, clinical evaluation, chest X-ray and response to therapy, 2) development of isolated large $T$ wave inversion $(\geq 10 \mathrm{~mm})$ defined as occurring in one or more precordial leads on a 12-lead ECG and surrounded by positive $\mathrm{T}$ waves after the initial presentation, 3 ) significant coronary artery disease excluded with a high degree of certainty. All patients underwent echocardiography. Rate correction for the QT intervals (QTc) was performed using Bazett's formula. Serum markers of myocardial injury were creatine kinase $(\mathrm{CK})$ and troponin Ic, samples were drawn at least twice, $6 \mathrm{~h}$ apart.

\section{Results}

Clinical characteristics of the three study patients are summarized in Table 1. Ages ranged from 50 to 72 years old. The three patients were women and two of them had a history of end-stage renal disease 
Table 1 Clinical characteristics of the three study patients

\begin{tabular}{|c|c|c|c|}
\hline Patient & 1 & 2 & 3 \\
\hline Age (years) & 50 & 72 & 60 \\
\hline Gender & Female & Female & Female \\
\hline Past medical history & $\begin{array}{l}\text { End-stage renal disease due to } \\
\text { familial nephronophtisis on } \\
\text { intermittent hemodialysis, diabetes, } \\
\text { hypertension }\end{array}$ & Hypertension, nontoxic goiter & $\begin{array}{l}\text { End-stage renal disease with } \\
4 \text { cerebral aneurysms due to adult } \\
\text { polycystic kidney disease on } \\
\text { intermittent hemodialysis, } \\
\text { hypertension }\end{array}$ \\
\hline Etiology & Hypertensive crisis + volume overload & Hypertensive crisis & Hypertensive crisis + volume overload \\
\hline Heart rate at presentation & 130 & 135 & 100 \\
\hline $\begin{array}{l}\text { Blood pressure at presentation } \\
(\mathrm{mmHg})\end{array}$ & $230 / 120$ & $220 / 110$ & $240 / 160$ \\
\hline $\begin{array}{l}\text { Localization of inverted T wave } \\
\text { (leads) }\end{array}$ & V1-V4 & V1-V3 & V1-V3 \\
\hline $\begin{array}{l}\text { Maximum amplitude of inverted } \\
\text { T wave }(\mathrm{mV})\end{array}$ & 1.4 & 2.0 & 1.1 \\
\hline QTc at presentation (ms) & 443 & 435 & 424 \\
\hline $\begin{array}{l}\text { Longest QTc in subsequent ECG } \\
\text { (ms) }\end{array}$ & 581 & 626 & 458 \\
\hline Markers of myocardial injury & Negative & Troponin Ic (up to $0.4 \mu \mathrm{g} / \mathrm{l}$ ) & Negative \\
\hline Echocardiogram & $\begin{array}{l}\text { LV hypertrophy, anteroapical } \\
\text { hypokinesis, EF 50\% }\end{array}$ & $\begin{array}{l}\text { Moderate LV dilation, moderate } \\
\text { mitral and aortic valve regurgitation, } \\
\text { normal wall motion, EF } 50 \%\end{array}$ & $\begin{array}{l}\text { No left ventricular dilation or } \\
\text { hypertrophy, moderate mitral valve } \\
\text { regurgitation, no segmental wall } \\
\text { motion abnormalities, EF } 45 \%\end{array}$ \\
\hline Coronary angiography & $\begin{array}{l}\text { Coronary sclerosis with } \\
\text { no significant stenosis }\end{array}$ & No coronary disease & Not performed \\
\hline Left ventriculography & Anteroapical hypokinesis, EF 52\% & Normal wall motion, EF $60 \%$ & Not performed \\
\hline
\end{tabular}

$E F$ ejection fraction, $L V$ left ventricular, $L A D$ left anterior descending coronary artery

on intermittent hemodialysis. None of the patients presented with chest pain, neurological symptoms or clinical suggestion of a central nervous system event or pheochromocytoma. The results of initial laboratory data were unremarkable. Other causes of large $\mathrm{T}$ wave inversion, including alteration of the ventricular activation sequence, were absent. Patients responded promptly to conventional management of acute pulmonary edema and did not require endotracheal intubation. They remained stable and asymptomatic thereafter. Echocardiographic results are summarized in Table 1. Significant coronary artery disease was ruled out by coronary angiography in two patients. For the third patient, coronary artery disease could be excluded with a high degree of certainty by absence of history of chest pain with index event, initial ECG, negative serum markers of myocardial injury, absence of segmental wall motion abnormalities and a normal coronary angiography performed two years earlier. The etiology in each case of pulmonary edema was a hypertensive crisis. In the two patients on intermittent dialysis a volume overload contributed to the clinical presentation.
The electrocardiographic findings are summarized in Table 1 and illustrated in Figures 1-3. All patients had left ventricular (LV) hypertrophy by voltage. QTc at presentation was normal. T wave inversion developed within $6 \mathrm{~h}$ in the three cases with the maximum amplitudes ranging from 1.1-2.0 $\mathrm{mV}$. Inverted $\mathrm{T}$ waves were recorded in the anterior chest leads V1-V4. The QT intervals were variably prolonged with corrected QT exceeding $600 \mathrm{~ms}$ in one case during $\mathrm{T}$ wave inversion.

In each case there was a gradual resolution of the $\mathrm{T}$ wave inversion and QT prolongation.

\section{Discussion}

Isolated $\mathrm{T}$ wave inversion recorded during an acute cardiac event generally signifies myocardial ischemia [1-3]. However it has long been recognized that coronary artery disease is less likely responsible when transient large $\mathrm{T}$ wave inversion with marked prolongation of the QT interval develops after an acute 
Fig. 1 Patient 1. a ECG on admission for acute pulmonary edema. b $16 \mathrm{~h}$ later, the ECG shows giant inverted T waves in leads V1-V4 and marked prolongation of the QT interval (QTc $581 \mathrm{~ms}$ )
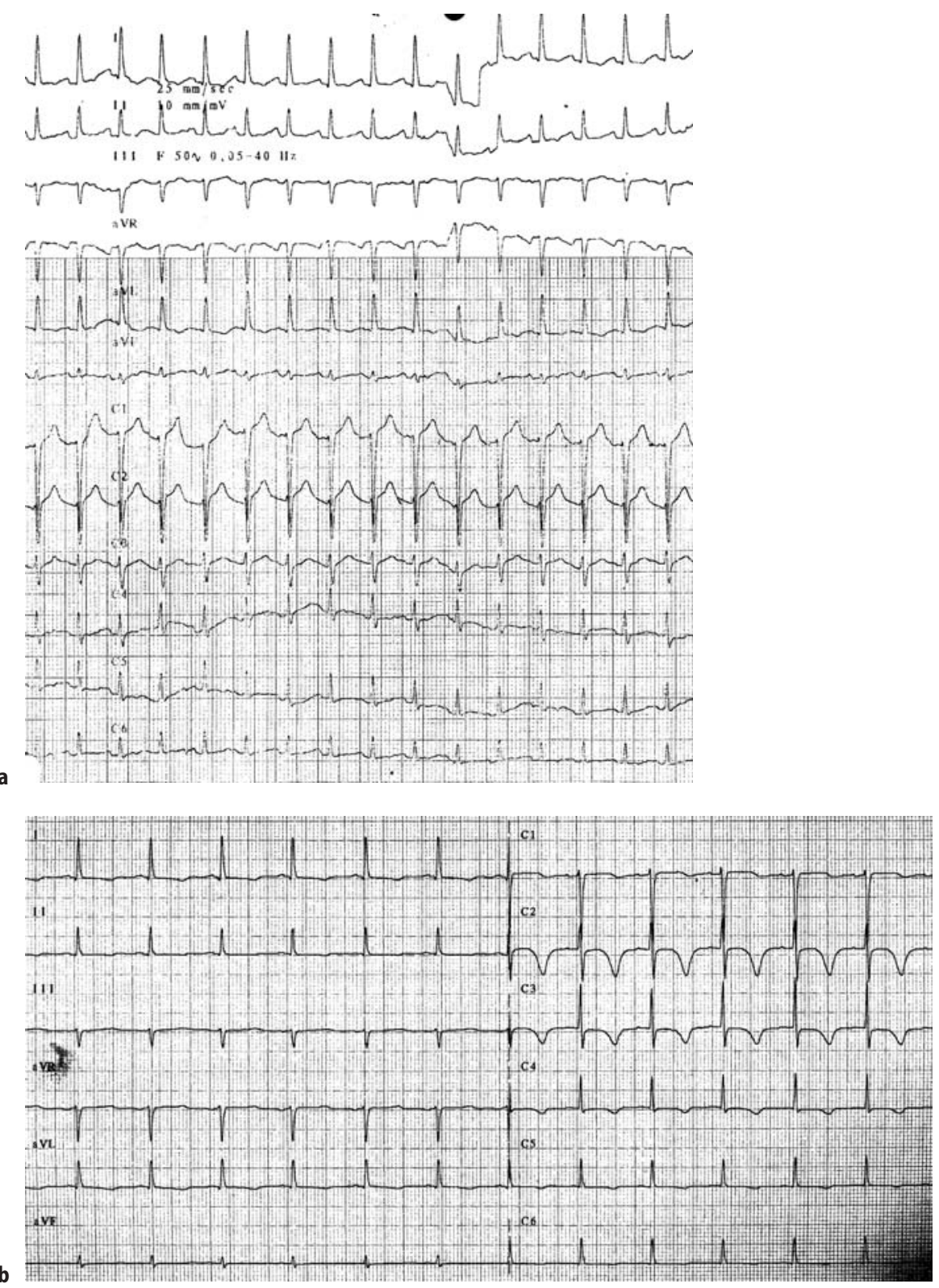

event. The most commonly reported association with this characteristic ECG pattern seems to be acute central nervous system disorders, primarily subarachnoid hemorrhage but also subdural hematoma, ischemic stroke, trauma and intracranial hemorrhage [4-6]. Similar T wave changes have been reported after bilateral carotid endarterectomy [7]. The massive $\mathrm{T}$ wave inversion seen in some patients following Stokes-Adams syncope may be related to a similar neurogenic mechanism [8]. Transient large $\mathrm{T}$ wave inversion has been associated with a variety of other conditions including pulmonary embolism [910], non-convulsive status epilepticus [11], theophyl- line toxicity [12], spontaneous pneumomediastinum [13], emotional stress [14], pheochromocytoma [15], cocaine use [16] and severe aortic regurgitation [17]. A novel cardiac syndrome, the transient left ventricular apical ballooning syndrome, also known as takotsubo cardiomyopathy, characterized by peculiar transient apical "ballooning" of the left ventricle and ECG changes mimicking acute myocardial infarction despite the absence of obstructive epicardial coronary artery disease is also associated with evolutionary deep inverted $\mathrm{T}$ waves $[18,19]$.

Furthermore there is an interesting form of $\mathrm{T}$ wave inversion consecutive to the alteration of the 
Fig. 2 Patient 2. a ECG on admission for acute pulmonary edema. $\mathbf{b} 8 \mathrm{~h}$ later, the ECG shows giant inverted T waves in leads V1-V3 and marked prolongation of the QT interval (QTc $626 \mathrm{~ms}$ )
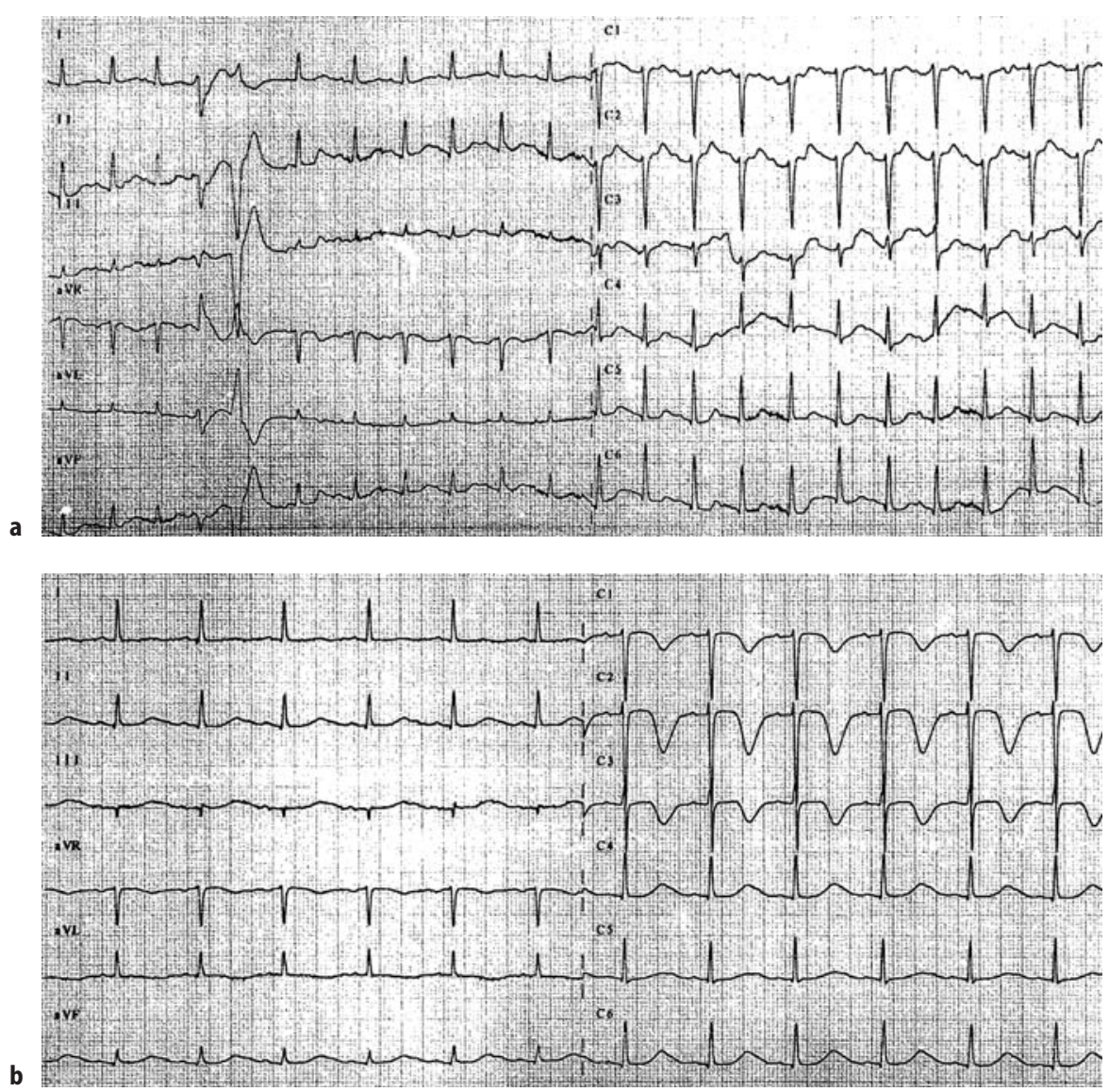

ventricular activation sequence. The term "cardiac memory $\mathrm{T}$ wave changes" has been used in such circumstances. It was first noted following ventricular pacing, with inverted $\mathrm{T}$ wave persisting long after resumption of sinus rhythm [20]. Similar T wave inversion has been recorded in intermittent left bundle branch block [21], following radiofrequency ablation of the accessory pathway in WPW [22], ventricular tachycardia [23] and other alteration of ventricular activation.

The cases presented here were accumulated over a 3 year period from a community-based hospital. Three patients were identified with large $\mathrm{T}$ wave inversion occurring in an isolated region of the precordial ECG leads after resolution of an acute pulmonary edema. The cause of pulmonary edema was a hypertensive crisis in each case. In two cases patients had a history of end-stage renal disease on intermittent hemodialysis and volume overload contributed to clinical presentation. The combination of acute pulmonary edema (which could have been interpreted as an angina equivalent) and delayed isolated inverted $\mathrm{T}$ waves was suggestive of the clinical and ECG criteria of the Wellens' syndrome. However, coronary artery disease was excluded by coronary angiography in two cases. In the third case, significant coronary artery disease was not excluded by angiography but could be ruled out with a high degree of certainty. The prompt response to conventional management of acute pulmonary edema and the fact that patients remained asymptomatic thereafter substantiate the postulated etiology of pulmonary edema.

Marked QT interval prolongation occurred in two cases, whereas in the third case the corrected QT interval was only slightly prolonged. The $\mathrm{T}$ wave inversion and QT prolongation developed after normalization of the clinical symptoms and within 6 hours after initial presentation. There was a gradual and simultaneous resolution of the $\mathrm{T}$ wave inversion and QT prolongation.

Our report does not allow a characterization of patients who present the described ECG pattern after resolution of acute pulmonary edema. However, it is important to notice that in each reported case the patient was female. A striking female preponderance has also been observed in various series of patients with large $\mathrm{T}$ wave inversion $[5,24,25]$.

The evolutionary deep $\mathrm{T}$ wave inversions with prolongation of the QT interval and the female pre- 
Fig. 3 Patient 3. a ECG on admission for acute pulmonary edema. $\mathbf{b}$ Hours later, the ECG shows giant inverted T waves in leads V1-V3 and slight prolongation of the QT interval (QTc $458 \mathrm{~ms}$ )
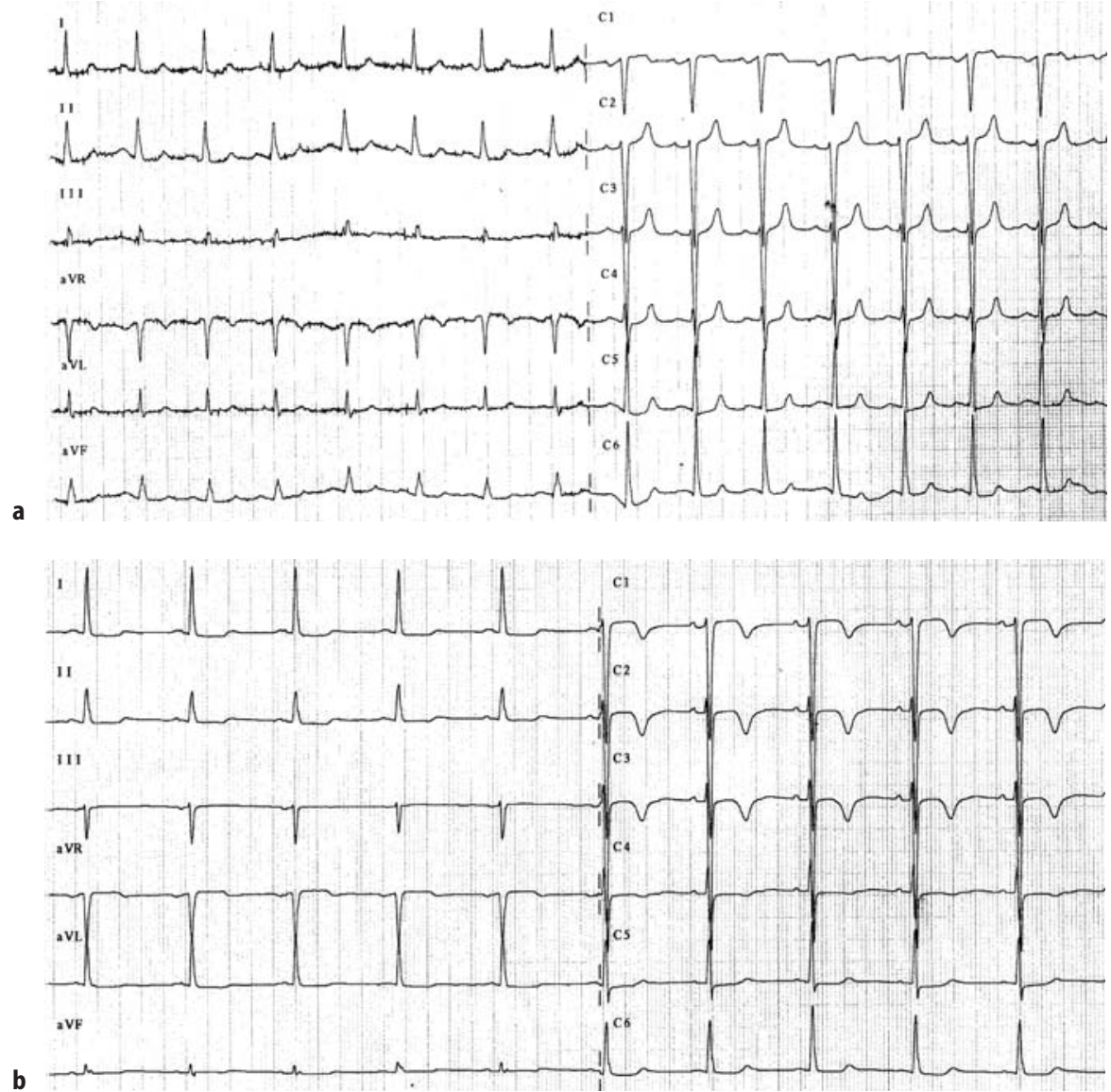

ponderance were also suggestive of the left ventricular apical ballooning syndrome since this condition is triggered in many cases by a physical stress (acute dyspnea in these particular cases). However, the peculiar transient apical ballooning of the left ventricle that defines this condition was not observed in the echocardiography performed in the acute phase.

To our knowledge acute pulmonary edema not related to an acute coronary event has not previously been recognized to cause delayed giant isolated $\mathrm{T}$ wave inversion after resolution of clinical symptoms. Littmann described a report of nine patients without known or suspected coronary artery disease who presented with acute pulmonary edema and subsequently developed diffuse $\mathrm{T}$ wave inversion and QT prolongation [25]. However, in that report, the ECG was characterized by diffuse negative $\mathrm{T}$ waves occurring in all precordial leads, whereas in our study $\mathrm{T}$ wave inversions occurred in an isolated region of the precordial leads.

We remain uncertain as to the cause of $\mathrm{T}$ wave inversion. Although significant coronary disease was essentially ruled out, a subendocardial ischemia may still be implicated. The hypertrophied left ventricu- lar muscle mass, the increased systolic pressure and the prolongation of ejection time all elevate myocardial oxygen consumption. Myocardial perfusion is impaired by the abnormally heightened pressure on the coronary arteries branches, the shortening of diastole and by the elevation of left ventricular enddiastolic pressure which lowers the coronary perfusion pressure gradient, thus leading to an imbalance between myocardial oxygen supply and demand. However, because of the prompt response to management of acute pulmonary edema with consecutive normalization of myocardial oxygen supply and demand, subendocardial ischemia would not explain why the ECG modifications took hours to occur and persisted for several days.

An alternative explanation for the observed $\mathrm{T}$ wave inversion in the precordial leads could involve the characteristic ECG pattern produced by acute right heart strain secondary to the sudden increase of pulmonary vascular resistance as described in pulmonary embolism. However, other signs of acute right ventricular overload as the S1Q3 or S1Q3T3 pattern, the rightward shift of the QRS axis, the right ventricular conduction defects and the clock- 
wise rotation were absent. Furthermore, this hypothesis would not explain the time lag between the acute phase of the pulmonary edema and the onset of ECG signs after clinical stabilization with consecutive normalization of the right ventricular load.

The ECG changes in our patients share many features with those occurring in patients with subarachnoid hemorrhage. These changes were initially thought to be the result of neural influences rather than myocardial damage. However microscopic evidence of myocardial injury was subsequently reported in these patients [26, 27]. Patients with subarachnoid hemorrhage and ECG abnormalities may also demonstrate corresponding regional wall motion abnormalities without stenosis or spasm of the epicardial coronary arteries $[28,29]$. The myocardial contraction abnormalities improve in the chronic stage as those in the postischemic stunned myocardium. Similar reversible anterior apical wall motion abnormalities were reported with a variety of other acute noncardiac illnesses in patients who developed deep $\mathrm{T}$ wave inversion in precordial leads [5]. All patients were acutely ill and coronary angiography excluded significant stenosis in the likely culprit artery in most patients. Thus evidence suggests that reversible myocardial contraction abnormalities may occur via mechanisms other than reduction in epicardial coronary blood flow. The sympathetic nervous system has been considered to be the genesis of the cardiac injury, probably mediated by vasoconstriction of intramural coronary arteries or by the direct toxic effect of catecholamines. Pharmacologic adrenergic stimulation has been shown to induce histological myocardial damage probably related to cyclic AMP-mediated calcium overload of the cell $[30,31]$. Experimentally, myocardial damage after brain death induced by a rapid increase in intracranial pressure could be prevented by total sympathectomy [32]. One study assessing the effect of propanolol and phentolamine on the clinical course of subarachnoid hemorrage showed that necrotic myocardial lesions were prevented by the pharmacologic sympathetic blockade [33]. While evidence suggests catecholamines can induce a reversible myocardial damage, it is unclear why the damage would be regional. Regional differences in sympathetic innervation could be one possible explanation.

A similar mechanism may have been operative for the observed T-QT changes in our study. ECG abnormalities were similar and all patients undoubtedly had intense activation of the sympathetic nervous system. Interestingly, the left ventriculogram performed in the acute phase demonstrated an anteroapical hypokinesis in one patient while echocardiography performed in the two other patients did not show any significant regional wall motion abnormality but rather a diffuse involvement of the left ventricle.

Thus, our case series describes three patients with large $\mathrm{T}$ wave inversion occurring in an isolated region of the precordial ECG leads after resolution of acute pulmonary edema. The cause of pulmonary edema was a hypertensive crisis in each case. The delayed development of this characteristic ECG pattern after an acute cardiac event was suggestive of the clinical and ECG criteria of the Wellens' syndrome but significant coronary disease was subsequently ruled out.

Prospective evaluation of patients who present with acute pulmonary edema would allow further knowledge of this ECG phenomenon. It would give us indications about the clinical and ECG criteria associated with noncoronary rather than coronary etiology. A better identification of these patients would allow hospital stays to be shortened without the need to proceed with further invasive diagnostic workup that would otherwise be warranted given the high incidence of anterior myocardial infarction within a matter of days in patients with the Wellens' syndrome treated medically.

\section{References}

1. De Zwann C, Bär FW, Wellens HJJ (1982) Characteristic electrocardiographic pattern indicating a critical stenosis high in left anterior descending coronary artery in patients admitted because of impending myocardial infarction. Am Heart J 103:730736
2. De Zwann C, Bär FW, Janssen JHA et al (1989) Angiographic and clinical characteristics of patients with unstable angina showing an ECG pattern indicating critical narrowing of the proximal LAD coronary artery. Am Heart J 117:657-665

3. Haines DE, Raabe DS, Gundel WD, Wackers FJT (1983) Anatomic and prognostic significance of new Twave inversion in unstable angina. Am J Cardiol 52:14-18
4. Macaulay W, Nikolic G (1988) Giant T wave inversion. Heart Lung 17:582583

5. Sharkey SW, Shear W, Hodges M, Herzog CA (1998) Reversible myocardial contraction abnormalities in patients with an acute noncardiac illness. Chest 114:98-105

6. Perron AD, Brady WJ (2000) Electrocardiographic manifestations of CNS events. Am J Emerg Med 18:715-720 
7. Baur HR, Pierach CA (1974) Electrocardiographic changes after bilateral carotid endarterectomy. New Engl J Med 291:1121-1122

8. Jacobson D, Schrire V (1966) Giant T wave inversion associated with Stokes-Adams syncope. S Afr Med J 40:641-646

9. Ferrari E, Imbert $A$, Chevalier T (1997) The ECG in pulmonary embolism: predictive value of negative $\mathrm{T}$ waves in precordial leads - 80 case reports. Chest 111:537-543

10. Medd WE, McBrien DJ (1962) Acute pulmonary embolism with electrocardiographic changes mimicking coronary-artery disease. Lancet 1:944-947

11. Spencer RGS, Cox TS, Kaplan PW (1998) Global T-wave inversion associated with nonconvulsive Status Epilepticus. Ann Intern Med 129:163164

12. Kolander SA, Nydegger CC, Porter RS (1989) T wave inversion associated with severe theophylline toxicity. Chest 96:429-431

13. Sakabe K, Fukuda N, Wakayama K, Nada T, Shinohara H, Tamura Y (2004) Spontaneous pneumomediastinum: a cause of T-wave inversion in electrocardiogram. Int J Cardiol 94: 123-126

14. Smith KL, Hancock EW (1993) Global T-wave inversion after a car accident. Hosp Pract 28:55-59

15. Cheng TO, Bashour TT (1976) Striking electrocardiographic changes associated with pheochromocytoma. Chest 70:397-399

16. Kossowsky WA, Lyon AF, Chou SY (1989) Acute non-Q wave cocaine-related myocardial infarction. Chest 96:617-621

17. Weston CFM, Fonfe G, Wahbi Z, Wilson JI (1996) Giant T wave inversion associated with severe aortic regurgitation. Int J Cardiol 54:277-282
18. Tsuchihashi $\mathrm{K}$, Ueshima K, Uchida $\mathrm{T}$, Oh-mura N, Kimura K, Owa M, Yoshiyama M, Miyazaki S, Haze K, Ogawa H, Honda T, Hase M, Kai R, Morii I, for the Angina Pectoris-Myocardial Infarction Investigations in Japan (2001) Transient left ventricular apical ballooning without coronary artery stenosis: a novel heart syndrome mimicking acute myocardial infarction. J Am Coll Cardiol 38:1118

19. Villareal RP, Achari A, Wilansky S, Wilson JM (2001) Anteroapical stunning and left ventricular outflow tract obstruction. Mayo Clin Proc 76:79-83

20. Chatterjee K, Harris A, Davies JG, Leatham A (1969) T-wave changes after artificial pacing. Lancet 1:759760

21. Denes P, Pick A, Miller RH, Pietras RJ, Rosen KM (1978) A characteristic precordial repolarization abnormality with intermittent left bundle-branch block. Ann Intern Med 89:55-57

22. Wood MA, DiMarco JP, Haines DE (1992) Electrographic abnormalities after radiofrequency catheter ablation of accesssory bypass tracts in the Wolff-Parkinson-White syndrome. Am J Cardiol 70:200-204

23. Kernohan RJ (1969) Post-paroxysmal tachycardia syndrome. Br Heart J 31: 803-806

24. Walder LA, Spodick DH (1991) Global T wave inversion. J Am Coll Cardiol 17:1479-1485

25. Littmann L (1999) Large T wave inversion and QT prolongation associated with pulmonary edema. A report of nine cases. J Am Coll Cardiol 34:1106-1110

26. Koskelo P, Punsar S, Sipila W (1964) Subendocardial haemorrhage and E.C.G. changes in intracranial bleeding. Br Med J 1:1479-1480
27. Doshi R, Neil-Dwyer G (1980) A clinicopathological study of patients following a subarachnoid hemorrage. J Neurosurg 52:295-301

28. Pollick C, Cujec B, Parker S, Tator C (1988) Left ventricular wall motion abnormalities in subarachnoid hemorrage: an echocardiographic study. J Am Coll Cardiol 12:600-605

29. Kono T, Morita H, Kuroiwa T, Onaka H, Takatsuka H, Fujiwara A (1994) Left ventricular wall motin abnormalities in patients with subarachnoid hemorrage: neurogenic stunned myocardium. J Am Coll Cardiol 24:636640

30. Todd GL, Baroldi G, Pieper GM, Clayton FC, Eliot RS (1985) Experimental catecholamine-induced myocardial necrosis. II. Temporal development of isoproterenol-induced contraction band lesions correlated with ECG, hemodynamic and biochemical changes. J Mol Cell Cardiol 17:647-656

31. Mann DL, Kent RL, Parsons B, Cooper G (1992) Adrenergic effects on the biology of the adult mammalian cardiocyte. Circulation 85:790-804

32. Novitzky D, Wicomb WN, Cooper DK, Rose AG, Reichart B (1986) Prevention of myocardial injury during brain death by total cardiac sympathectomy in the Chacma baboon. Ann Thorac Surg 41:520-524

33. Neil-Dwyer G, Walter P, Cruickshank JM, Doshi B, O'Gorman P (1978) Effect of propanolol and phentolamine on myocardial necrosis after subarachnoid haemorrhage. $\mathrm{Br}$ Med J 2:990-992 